\title{
Phosphatidylinositol 3-kinase p110ס expression in Merkel cell carcinoma
}

\author{
Emil Chteinberg ${ }^{1,2,3}$, Dorit Rennspiess ${ }^{1}$, Ryan Sambo ${ }^{1}$, Samantha Tauchmann ${ }^{1}$, \\ Nicole W.J. Kelleners-Smeets ${ }^{4}$, Véronique Winnepenninckx ${ }^{1}$, Ernst-Jan Speel $^{1}$, \\ Anna Kordelia Kurz ${ }^{5}$, Martin Zenke ${ }^{2,3}$ and Axel zur Hausen ${ }^{1}$

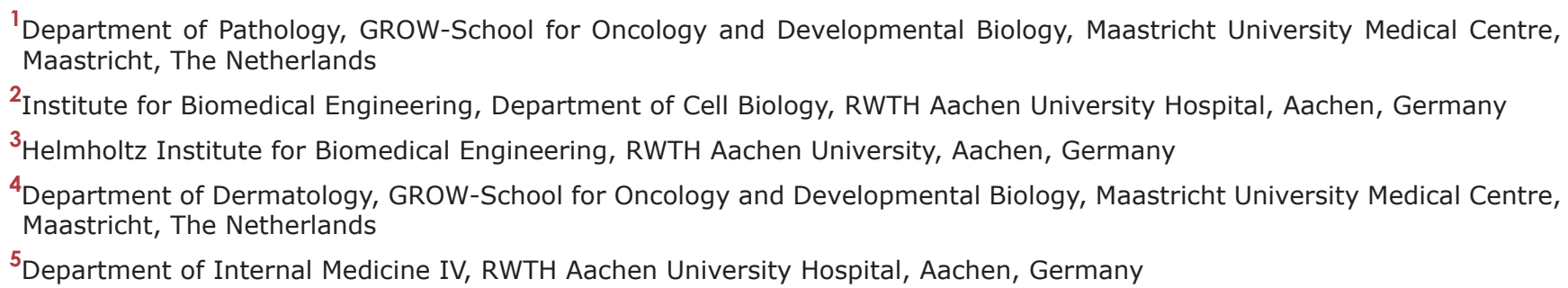

Correspondence to: Axel zur Hausen, email: axel.zurhausen@mumc.nl

Keywords: Merkel cell carcinoma; phosphatidylinositol 3-kinase; chemotherapeutics

Received: February 05, $2018 \quad$ Accepted: May 31, $2018 \quad$ Published: July 03, 2018

Copyright: Chteinberg et al. This is an open-access article distributed under the terms of the Creative Commons Attribution License 3.0 (CC BY 3.0), which permits unrestricted use, distribution, and reproduction in any medium, provided the original author and source are credited.

\section{ABSTRACT}

The prognosis of stage III/IV Merkel cell carcinoma (MCC) is very poor. The Phosphatidylinositol 3-kinase p110d specific inhibitor idelalisib has recently been reported to induce complete clinical remission in a stage IV MCC patient. Here we assessed the expression of p1100 in primary MCC and MCC cell lines including its functionality.

Immunofluorescence microscopy revealed a specific cytoplasmic p110ס expression in $71.4 \%$ of the tested MCCs and in all tested MCC cell lines. Compared to the B cell leukemia cell line REH all MCC cell lines, except MKL-1, revealed a lower response towards the treatment with idelalisib. MKL-1 showed a 10-fold higher IC $_{50}$ compared to REH which was accompanied by a significant decrease of Akt phosphorylation. However, treating the MCC cells with the specific PI3K p110a subunit inhibitor BYL719 led to a more effective decrease of the cell viability compared to idelalisib: WaGa cells 30-fold, PeTa cells 15-fold and all other MCC cell lines 3-fold.

Although PI3K p110ס is expressed in the majority of MCCs and cell lines its inhibition by idelalisib alone does not suffice to effectively affect MCC cells viability.

\section{INTRODUCTION}

Merkel cell carcinoma (MCC) is a very aggressive virus associated non-melanoma human skin cancer [1-3]. The Merkel cell polyomavirus (MCPyV) is clonally integrated in more than $80 \%$ of the MCCs $[4,5]$ and it has been shown that the expression of the oncogenic T-antigens are important drivers for the oncogenesis of MCC [6,7]. Next to MCPyV, UV exposure, age and immune deficiency are contributing to the pathogenesis of MCC [1]. In addition, the risk to develop MCC is significantly increased upon solid organ transplantation (23.8-fold) and for HIV patients (11-fold) [8, 9].

Despite its rarity the incidence of MCC has tripled in the USA and Europe [1]. This and the low 5-year survival rate of $20 \%$ of MCCs with distant metastasis emphasizes the need for a unique treatment [10]. Recently, a complete clinical response induced by the phosphoinositide 3-kinase (PI3K) p1108 selective inhibitor idelalisib in a patient with stage IV - with proven p $110 \delta$ transcript expression 
by quantitative RT-PCR - has been reported by Shiver et al. [11].

The activity of the PI3K-pathway has already been studied in MCC by inhibiting the $\mathrm{p} 110 \alpha$ subunit [12, 13]. Yet, it remains unclear to which extent the transcript expression of PI3K p110 $\delta$ leads to a significant specific protein expression in MCC and to which extent $\mathrm{p} 110 \delta$ contributes to the PI3K pathway activity in MCC. It is expected that elucidating PI3K p110 $\delta$ activity in MCC might help to identify potential additional therapeutic options for this currently poorly treatable non-melanoma skin cancer.

Here we assessed the expression of $\mathrm{p} 110 \delta$ in 21 MCC tissues and $7 \mathrm{MCC}$ cell lines. The functionality of p110 $\delta$ was analyzed by idelalisib treatment of MCC cell lines and compared to the $\mathrm{p} 110 \alpha$ subunit by treatment with the $\mathrm{p} 110 \alpha$ specific inhibitor BYL719.

\section{RESULTS}

\section{Expression of PI3K p110 in MCC}

The expression of PI3K p110 was analyzed in 18 primary and in three metastatic MCCs by immunofluorescence microscopy (IFM). A specific cytoplasmic staining could be observed in 13 of 18 primary MCC $(72.2 \%)$ and in 2 out of 3 metastatic MCC (66.6\%) (Table 1 and Figure 1). The MCPyV status of all tested MCC tissues was assessed, an example of one MCPyV-positive and one MCPyV-negative tissue is shown in Supplementary Figure 1. 3 out of 18 primary MCCs were negative for MCPyV, which were positive for the p110 subunit.

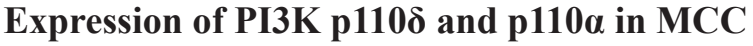 cell lines}

In addition, the expression of the PI3K p $110 \alpha$ and PI3K p110 $\delta$ was assessed in the MCC cell lines MKL-1, MKL-2, WaGa, PeTa, MCC13 and MCC26. The B-ALL cell line REH was used as positive control and the human multiple myeloma cell line U266 as negative control (Figure 2A) [14]. A strong protein band at the expected size of PI3K p $110 \delta$ of $119 \mathrm{kDa}$ could be observed for the cell lysate of REH. Thinner protein bands were also visible in the MCPyV-positive and MCPyV-negative cell line lysates and completely absent in U266 cell lysate. In comparison, all cell line lysates showed a strong protein band at $119 \mathrm{kDa}$ specific for PI3K p110 (Figure 2A). The results for the $\mathrm{p} 110 \delta$ subunit were confirmed by immunofluorescence microscopy (IFM): in all cell lines except U266 a specific cytoplasmic staining could be detected (Figure 2B). Thus, PI3K p110 $\delta$ is expressed in the majority of primary and metastatic MCCs and in MCC cell lines irrespective of the MCPyV status.

\section{Treatment with PI3K inhibitors}

The cell lines were tested for their sensitivity towards the PI3K p1108 specific inhibitor idelalisib. A decrease of the cell viability of almost all treated cell lines was observed after $120 \mathrm{~h}$ incubation. The best response was observed in the B-ALL cell line $\mathrm{REH}$ with an $\mathrm{IC}_{50}$ of $3.1 \mu \mathrm{M}$. The cell lines MKL-2, WaGa, PeTa and MCC13 showed for the idelalisib treatment almost a comparable range of $\mathrm{IC}_{50} 50 \mu \mathrm{M}$ to $63 \mu \mathrm{M}$. The MKL-1 cells were 2 -fold more sensitive compared to all other MCC cell lines. MCC26 cells showed a 1.4- to 1.6-fold weaker response compared to all other MCC cell lines. The multiple myeloma cell line U266 showed a decrease of the cell viability at a concentration of $12.5 \mu \mathrm{M}$, an $\mathrm{IC}_{50}$ value could not be determined for this PI3K p1108-negative cell line. In general, all MCC cell lines showed with an overall $p$-value $<0.001$ a significant dose-dependent sensitivity to idelalisib after $120 \mathrm{~h}$ incubation (Figure 3 and Table 2).

The effect of idelalisib on the PI3K pathway of the treated cell lines was tested by Western blotting analyzing the threonine 308 phosphorylation of protein kinase B (AKT) which is located downstream of PI3K. A significant decrease of AKT phosphorylation was restricted to REH and MKL-1 with increasing concentrations of idelalisib (Figure 4).

In addition, the MCC cell lines and the B-ALL cell line REH were treated with the specific PI3K p110 $\alpha$ inhibitor BYL719. In general, all cell lines showed a higher sensitivity towards BYL719 treatment compared to the idelalisib treatment. Again, REH showed the strongest response compared to all other cell lines. The MCPyVpositive cell lines $\mathrm{WaGa}$ and PeTa were more sensitive for BYL719 compared to MKL-1 and MKL-2 (Figure 3 and Table 2).

\section{DISCUSSION}

Under physiological conditions the PI3K p1108 subunit plays an important role in the differentiation of early B-cells into mature B-cells [15]. In the present study, we tested the expression and functionality of PI3K p $110 \delta$ in MCC. Using IFM we found that $71 \%$ of MCC tested, revealed a specific cytoplasmic expression of the p110 $\delta$ subunit. Prior to the use of IFM we had checked the monoclonal antibody for its specificity using Western blotting. All MCC cell lines were PI3K p110 positive by Western blotting as confirmed by IFM. The B-ALL cell line REH revealed the highest protein PI3K p110 $\delta$ expression compared to the other cell lines. To the best of our knowledge this is the first proof of PI3K p110 protein expression in MCC tissues and MCC cell lines. Previously, Shiver et al. have reported PI3K p110 expression on the transcript level in one MCC sample of a stage IV MCC patient [11]. This patient was treated with combined radiotherapy and idelalisib 
Table 1: Clinico-pathological data of MCC patients and corresponding tissues including the results of PI3K p110ס expression as tested by immunofluorescence microscopy (IFM)

\begin{tabular}{|c|c|c|c|c|c|c|c|c|}
\hline \multicolumn{9}{|c|}{ primary MCCs } \\
\hline ID & & gender & age & location & $d x$ & histo. & MCPyV & PI3K p1108 \\
\hline 1 & & $\mathrm{~m}$ & 63 & head & MCC & int. & pos. & + \\
\hline 2 & & $\mathrm{~m}$ & 92 & ear & $\mathrm{MCC}$ & s.c. & neg. & ++ \\
\hline 3 & & $\mathrm{f}$ & 85 & buttocks & $\mathrm{MCC}$ & s.c. & pos. & ++ \\
\hline 4 & & $\mathrm{~m}$ & 69 & lip & $\mathrm{MCC}$ & int. & pos. & ++ \\
\hline 5 & & $\mathrm{f}$ & 93 & upper eye lid & MCC & int. & pos. & theterogen. \\
\hline 6 & & $\mathrm{f}$ & 60 & tongue & MCC & int./s.c. & pos. & - \\
\hline 7 & & $\mathrm{~m}$ & 74 & upper leg & $\mathrm{MCC}$ & int. & pos. & - \\
\hline 8 & & $\mathrm{~m}$ & 93 & head & MCC & int. & neg. & ++ \\
\hline 9 & & $\mathrm{f}$ & 76 & buccal & MCC & int. & pos. & - \\
\hline 12 & & $\mathrm{f}$ & 83 & upper eye lid & $\mathrm{MCC}$ & int. & pos. & ++ \\
\hline 14 & & $\mathrm{~m}$ & 74 & upper leg & MCC & int. & pos. & ++ \\
\hline 15 & & $\mathrm{~m}$ & 77 & neck & MCC & int. & neg. & ++ \\
\hline 16 & & $\mathrm{f}$ & 66 & arm & MCC & int. & pos. & ++ \\
\hline 17 & & $\mathrm{~m}$ & 79 & head & MCC & int. & pos. & - \\
\hline 19 & & $\mathrm{~m}$ & 68 & buttocks & MCC & int. & pos. & ++ \\
\hline 20 & & $\mathrm{f}$ & 58 & buccal & MCC & int./s.c. & pos. & ++ \\
\hline 24 & & $\mathrm{~m}$ & 74 & upper leg & MCC & int. & pos. & - \\
\hline 30 & & $\mathrm{~m}$ & 63 & upper lip & MCC & int. & pos. & ++ \\
\hline \multicolumn{9}{|c|}{ metastases MCC } \\
\hline ID & gender & age & & location & $d x$ & histo. & MCPyV & PI3K p110d \\
\hline 21 & $\mathrm{~m}$ & 71 & & pancreas & MCC met. & int. & pos. & + \\
\hline 22 & $\mathrm{f}$ & 75 & & LN neck & MCC met. & int. & pos. & ++ \\
\hline 25 & $\mathrm{f}$ & 66 & & upper leg & MCC met. & int. & pos. & - \\
\hline
\end{tabular}

Abbreviations: $\mathrm{ID}=$ identity; $\mathrm{m}=$ male; $\mathrm{f}=$ female; $\mathrm{dx}=$ diagnosis; $\mathrm{LN}=$ lymph node $\mathrm{MCC}=$ Merkel cell carcinoma; Histo= histological subtype; int. = intermediate; s. c. $=$ small cell; $\mathrm{MCPyV}=$ Merkel cell polyomavirus; $\mathrm{IHC}=$ immunohistochemistry; pos. $=$ positive; neg. $=$ negative; heterogen. $=$ heterogeneous; $-=$ no expression; $+=$ weak expression; $++=$ moderate expression; $+++=$ strong expression; met. $=$ metastasis.

which is a selective PI3K p1108 inhibitor, that has effectively been used in the treatment of chronic lymphocytic leukemia (CLL), B-ALL and Hodgkin lymphoma (HL) [16]. In our cell culture treatment assay idelalisib significantly affected the cell viability of all MCC cell lines. However, compared to the B-ALL cell line REH this decrease of the cell viability has to be interpreted as weak.

The results of our analysis of the PI3K downstream pathway could possibly provide an explanation for the weak response of the MCC cell lines towards idelalisib treatment. Since AKT becomes phosphorylated upon PI3K activation we analyzed the phosphorylation status of AKT in the MCC cell lines. Of interest, only MKL-1 showed a decrease of phosphorylated AKT with increasing concentrations of idelalisib. Although this effect was 10fold weaker as compared to the B-ALL cell line REH, MKL-1 was the only MCC cell line which revealed a comparable effect as seen in REH cells implying that PI3K p110 is functional in MKL-1.

Functional PI3K p $110 \delta$ is primarily restricted to leukocytes and has been reported to be critical for the activation, proliferation and survival of B-cells [17] and the differentiation of pre-pro B-cells in pro B-cells [15]. Thus, together with the recently reported pre-pro/ pro- B- cell differentiation of MCC, i.e. TdT and PAX5 , immunoglobulin (Ig) expression and Ig rearrangements $[18,19]$, the functional PI3K p110 $\delta$ expression in MCC might add another tesserae in the discussion of the cellular origin of MCC.

The inhibition of the PI3K p110 $\alpha$ by BYL719 of the same cell lines has revealed a stronger impact on the MCC cell lines. The cell line REH showed again the best response towards the treatment with BYL719, followed by WaGa, PeTa, MKL-1, MKL-2, MCC26 and MCC13. 
Hafner and colleagues had treated the MCC cell lines WaGa, MKL-1, MKL-2 and MCC13 with another PI3K p110 $\alpha$ inhibitor LY-294002 [13]. They report $\mathrm{IC}_{50}$ values which are 6-fold, for WaGa, 1.6-fold for MKL-1, 1.8-fold for MKL-2 and 1.5-fold for MCC13 lower as compared to the calculated concentrations for BYL719. This might indicate that BYL719 is either more specific for the alpha subunit or is easier penetrating the cells. However, the order of the response to the drugs is still the same, WaGa cells are most responsive to the treatments followed by MKL-1, MKL-2 and MCC13 [13].

This strong impact on the MCC cell lines is not observed with idelalisib treatment rendering $\mathrm{PI} 3 \mathrm{~K}$ p110 $\delta$ expression and/or function less important for cell viability and for the PI3K pathway function of almost all MCC cell lines tested as shown by the unaltered pAKT concentration. Of interest, recent reports have addressed the mechanism of idelalisib resistance in leukemia cells
[20-22] and report PI3K p110 $\alpha$ upregulating mutations and upregulation of the downstream target in the Src family kinase (SFK) and Wnt pathway as underlying mechanisms for the resistance towards idelalisib treatment. According to the Western blotting results in this study of the p110 $\alpha$ and $\mathrm{p} 110 \delta$ detection in the treated cell lines, a much higher expression of $\mathrm{p} 110 \alpha$ compared to $\mathrm{p} 110 \delta$ is found. In combination with the much more effective treatment with BYL-719 compared to idelalisib, our data indicate that the resistance might also here be based on the higher level of p $110 \alpha$ expression compared to p110 $\delta$ in MCC cell lines.

To what extent the findings of our study add to the understanding of the recent case report of Shiver et al. (10) cannot completely be resolved, because the patient described by Shiver et al. did also receive radiotherapy. Iyer and colleagues described single-fraction radiation therapy for MCCs as a convenient alternative for chemotherapy [23]. So it might be that radiotherapy

\section{DAPI and PI3K p110反}
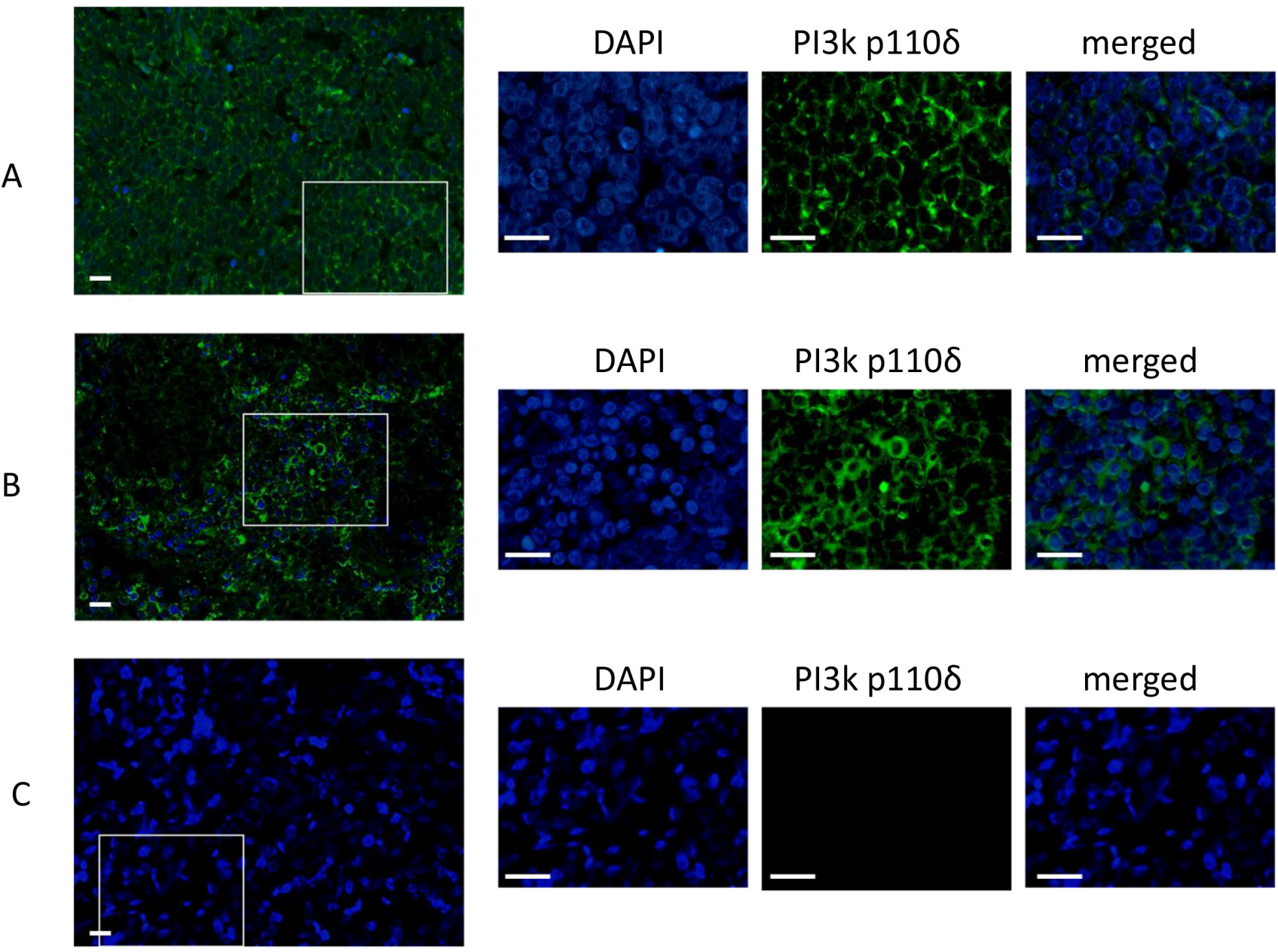

Figure 1: Immunofluorescence staining of PI3K p110 in MCCs. The IFM photographs of three MCCs ID14 (A), ID15 (B) and ID7 (C). The wide merged photographs (DAPI staining and PI3K p110 $)$ ) were taken at a magnitude of $10 \times$. The squares in the pictures indicate the region which is chosen for an image enlargement which was taken at a magnitude of $63 \times$. The enlarged pictures show separately the nucleus by the DAPI staining and the PI3K p110 staining. The merged pictures show a specific cytoplasmic staining of the p110 $\delta$ subunit in ID14 (A) and ID15 (B). ID7 (C) is an example of a p110 $\delta$ negative MCC. The scale bares represent a length of $100 \mu \mathrm{m}$. 
A

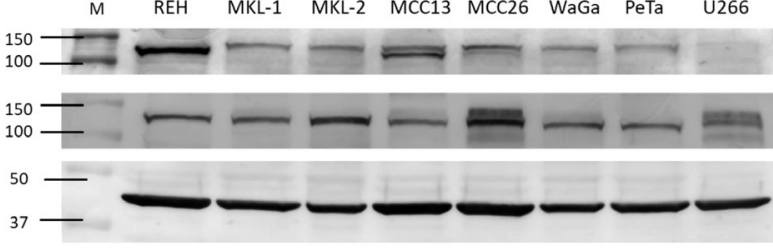

PI3K p110 \&

(110 kDa)

PI3K p110 $\alpha$

(110 kDa)

$\beta$-actin

(42 kDA)

B

MKL-1
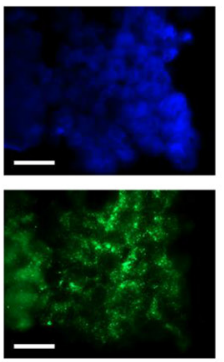

p1108

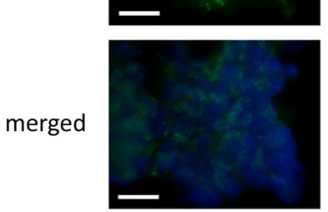

MKL-2
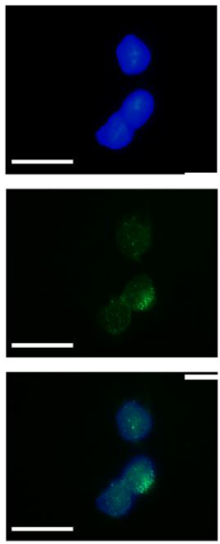

WaGa
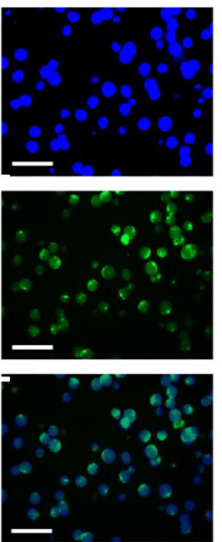

PeTa
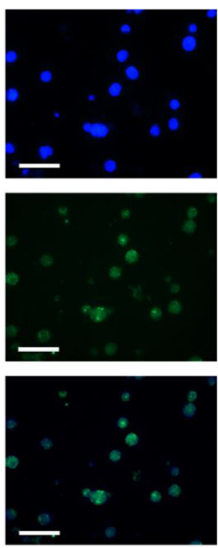

MCC13
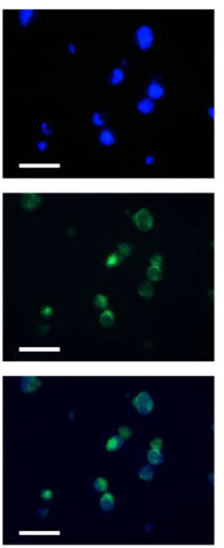

MCC26
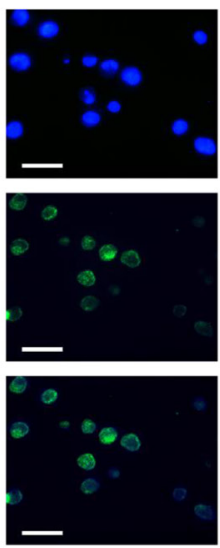

U266
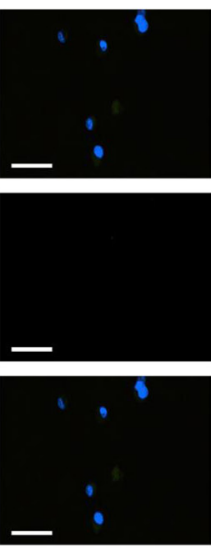

Figure 2: Assessment of PI3K p110 expression by Western blotting (A) and immunofluorescence microscopy (B). (A) Expression level of PI3K p110 $\delta$ and PI3K p110 $\alpha$ in cell lysates of REH, MKL-1, MKL-2, WaGa, PeTa, MCC13, MCC26, and U266. All cell lines except U266 (PI3K

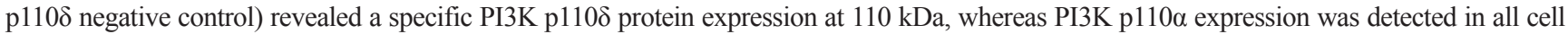
lines. The loading control $\beta$-actin is located at $42 \mathrm{kDa}$. (B) The corresponding IFM photographs for DAPI, PI3K p110 $\delta$ and merged are shown for these cell lines. The merged photograph identifies PI3K p110 $\delta$ expression within the cytoplasm. According to Figure $2 \mathrm{~A}$ U266 cells reveal no detectable PI3K p110 $\delta$ expression by IFM. The photos were taken with $63 \times$ magnification. The scale bars represent a length of $100 \mu \mathrm{m}$.
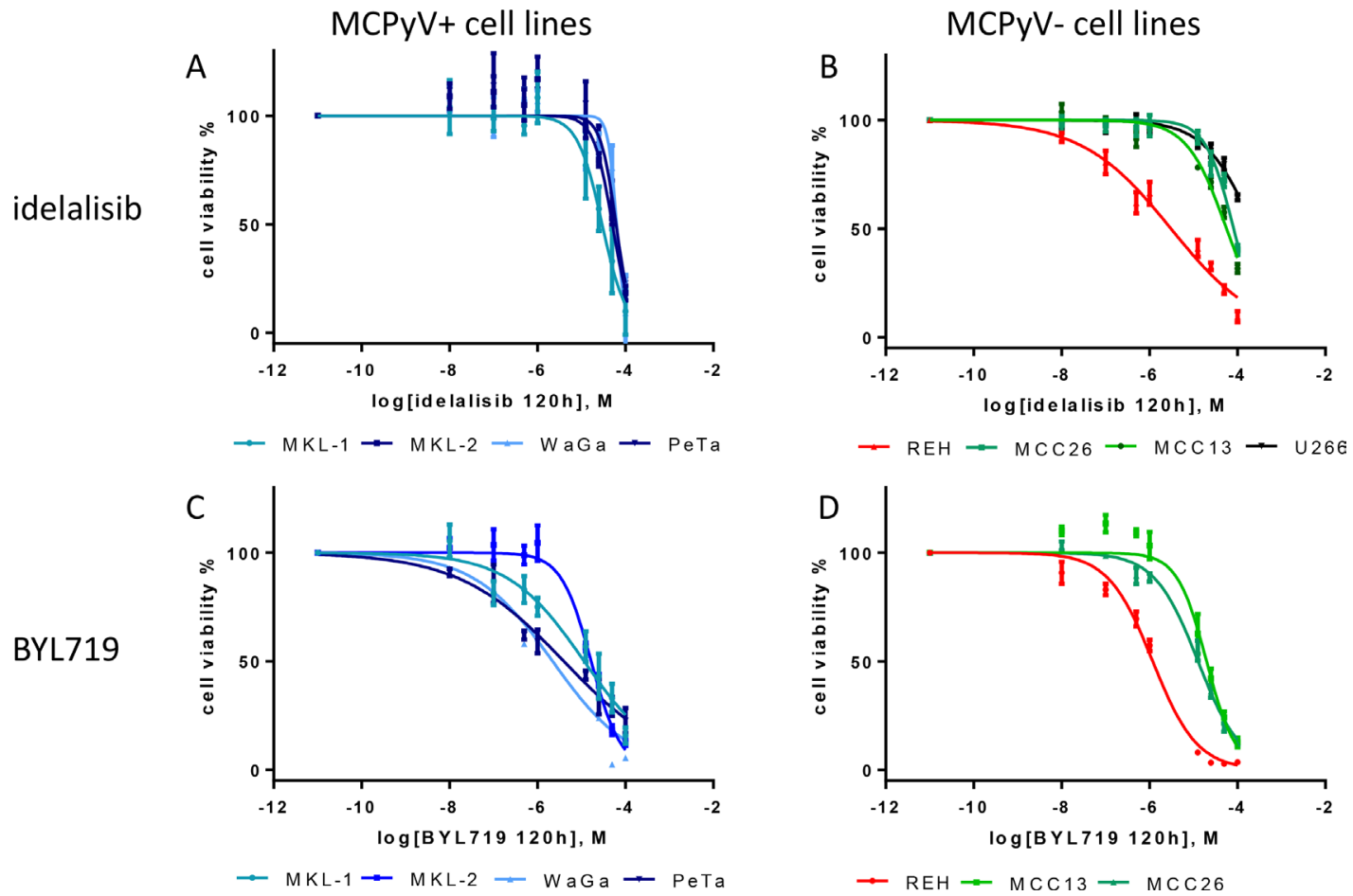

Figure 3: Dose-response curves of the MCPyV-positive MKL-1, MKL-2, WaGa, PeTa (A and C), and MCPyV-negative MCC13, MCC26, REH and U266 (B and D) cell lines after $120 \mathrm{~h}$ treatment with varying molar concentrations [M] of idelalisib and BYL719. The cell viability is inhibited by idelalisib or BYL719 in all cell lines in a dose-dependent manner. IC $_{50}$ were calculated from 3 independent $(n=3)$ experiments with eight replicates each. Bars symbolize the standard deviation of the mean. The overall $p$ values of all dose response curves besided the treatment of U266 are $<0.001$. 
Table 2: IC $_{50}$ values of idelalisib and BYL719 treatment of MCC, B-ALL and multiple myeloma cell lines

\begin{tabular}{lcccc}
\hline cell lines & cancer type & MCPyV & IC $_{\mathbf{5 0}}$ idelalisib $(\boldsymbol{\mu M})$ & $\mathbf{I C}_{\mathbf{5 0}} \mathbf{B y l 7 1 9}_{(\boldsymbol{M} \mathbf{M})}$ \\
\hline MKL-1 & MCC & pos. & 29.6 & 11.5 \\
MKL-2 & MCC & pos. & 50.7 & 16.6 \\
WaGa & MCC & pos. & 63.1 & 2.2 \\
PeTa & MCC & pos. & 59.2 & 4.2 \\
MCC13 & MCC & neg. & 56.5 & 20.0 \\
MCC26 & MCC & neg. & 81.9 & 12.7 \\
REH & B-ALL & neg. & 3.1 & 1.2 \\
U266 & multiple myeloma & neg. & not deter. & n.d. \\
\hline
\end{tabular}

Abbreviations: $\mathrm{IC}_{50}=$ half maximal inhibitory concentration, $\mathrm{B}-\mathrm{ALL}=\mathrm{B}$ cell acute lymphoblastic leukemia pos.= positive; neg.= negative; not. deter. $=$ not determinable adjusted in the manuscript, n.d. $=$ not done.

alone or in combination with idelalisib has led to the full remission of MCC [11].

\section{MATERIALS AND METHODS}

\section{Patient samples}

Twenty-one formalin fixed and paraffin embedded (FFPE) MCC tissues, 18 primary and 3 metastases, were obtained from the archives of the Department of Pathology,
Maastricht University Medical Center +, Maastricht, the Netherlands. All use of tissue and patient data is in agreement with the Dutch Code of Conduct for Observational Research with Personal Data (2004) and Tissue (2001, "www.federa. $\mathrm{org} /$ sites/default/files/digital_version_first part_code of_conduct_in_uk_2011_12092012.pdf”). $\quad \overline{M C C}$ have been defined by histology and immunohistochemistry for cytokeratin 20 (CK20), neural cell adhesion molecule (CD56), synaptophysin, chromogranin A and MCPyV (anti-large T antibody CM2B4, SANTA CRUZ

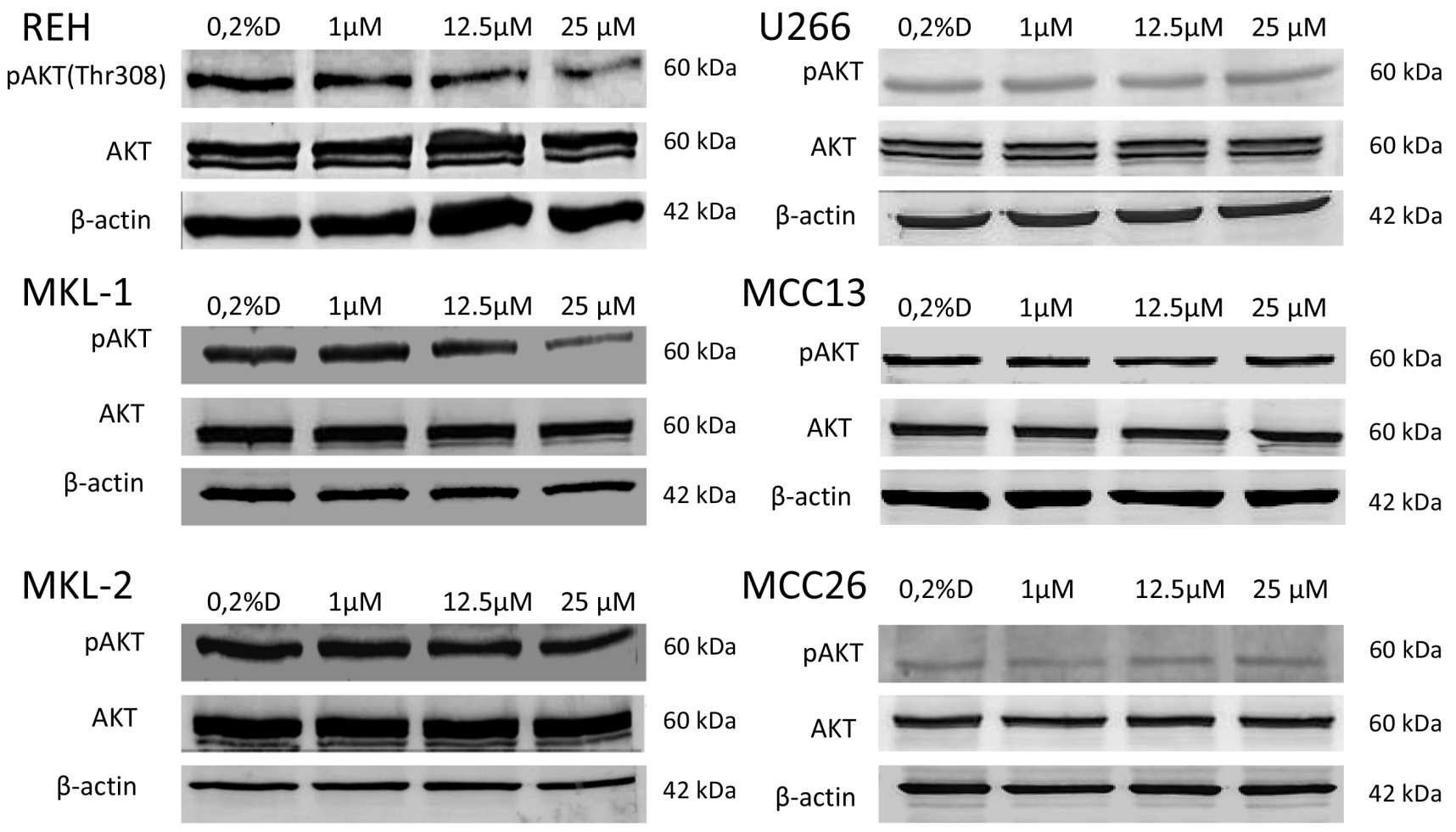

Figure 4: Western blotting of AKT phosphorylation (p-AKT) in idelalisib treated cell lines REH, MKL-1, MKL-2, MCC13, MCC26 and U266. For p-AKT and AKT a t $60 \mathrm{kDa}$ protein band could be detected in all cell lines. Only in the MCC cell line MKL-1 and the B-ALL cell line REH a decrease of p-AKT protein band density with increasing idelalisib concentrations could be observed. AKT and $\beta$-actin $(42 \mathrm{kDa})$ was used as a loading control. $0.2 \%$ DMSO $(0.2 \% \mathrm{D})$ without idelalisib were used as a treatment negative control. 
BIOTECHNOLOGY) and have been reviewed by 2 experienced pathologists (VW, AZH).

\section{Cell lines}

The MCPyV-positive MCC cell lines MKL-1, MKL-2, WaGa, PeTa; the MCPyV-negative MCC cell lines MCC13, MCC26 and the B-ALL cell line REH were used. All MCC cell lines were kindly provided by Jürgen Becker (University Hospital Essen, Essen, Germany). REH was obtained from the Leibniz Institute DSMZ-German Collection of Microorganisms and Cell Cultures. The multiple myeloma cell line U266 was kindly provided by Department of Transplantation Immunology, Tissue Typing Laboratory from the Maastricht Medical Center, NL. As described by Ikeda and colleagues U266 is negative for the PI3K p110 subunit [14], and thus served as negative control in this study. The cell lines were cultured in Gibco ${ }^{\circledR}$ RPMI 1640 medium (Life-science) with $10 \%$ fetal calf serum (FCS) $\left(\right.$ Gibco $^{\circledR}$, Thermo Fisher Scientific) in an incubator at $37^{\circ} \mathrm{C}$ and $5 \% \mathrm{CO}_{2}$.

\section{Western blotting}

The MCPyV-positive cell lines MKL-1, MKL-2, WaGa, PeTa and MCPyV-negative cell lines MCC13, MCC26 and the B-ALL cell line REH were grown in T25 flasks $\left(25 \mathrm{~cm}^{2}\right)$. The cells were harvested, pelleted, washed with cold PBS and resuspended in protein stabilizing buffer which consists of CHAPS Cell Extract Buffer (cell signaling technology) and phosphatase-protein inhibitor cocktail (Thermo Fisher Scientific). The proteins were isolated by freezing and thawing cycles by using liquid nitrogen. The protein concentration was determined by using the Pierce ${ }^{\mathrm{TM}}$ BCA Protein Assay Kit (Thermo Fisher Scientific) according to the manufacturer's instructions. 35-60 $\mu \mathrm{g}$ protein samples were separated by SDS-PAGE in $12 \%(\mathrm{w} / \mathrm{v})$ polyacrylamide gels, transferred to nitrocellulose membranes according to the manufacturer's instructions using Bio-Rad Mini Protean tetra systems. Followed by blocking with 5\% BSA (Sigma), incubated with primary antibodies anti-PI3K p1008 A-8 1:300 (SANTA CRUZ BIOTECHNOLOGY); PI3K p100 $\alpha$ antibody 1:1000 (cell signaling technologies), AKT antibody 1:1000 (cell signaling technologies) and pAKT (Thr308) antibody 1:1000 (cell signaling technologies) and monoclonal anti- $\beta$-actin antibody clone AC-15 1:10000 (Sigmal-Aldrich) diluted in blocking buffer and incubated over night at $4^{\circ} \mathrm{C}$, washed and incubated with the secondary antibody Alkaline Phosphatase AffiniPure $\mathrm{F}\left(\mathrm{ab}^{\prime}\right)_{2}$ Fragment Goat Anti-Mouse/Rabbit IgG + IgM $(\mathrm{H}+\mathrm{L})$ (Jackson ImmunoResearch). The blots were developed by NBT/BCIP (Thermo Fisher Scientific) incubation according to the manufacturer's instructions. The blots were scanned using Canon CanoScan 9000F Mark II.

\section{Immunofluorescence microscopy}

The expression of PI3K p110 $\delta$ was assessed by immunofluorescence microscopy (IFM) in 18 primary and 3 metastatic MCCs, MCPyV-positive MCC cell lines MKL-1, MKL-2, WaGa, PeTa and MCPyV-negative MCC cell lines MCC13 and MCC26. Further the expression of PI3K p110 $\delta$ was analyzed in the B cell acute lymphoblastic leukemia (B-ALL) cell line REH. All samples were formalin fixed and paraffin embedded. The FFPE sections were deparaffinized and rehydrated in xylene and ethanol baths. The antigen retrieval was performed by boiling the slides in $1 \mathrm{mM}$ EDTA pH 8.0. The slides were blocked in $5 \%$ BSA TBST, incubated with the first antibody anti-PI3K p100 $\delta$ antibody A-8 (SANTA CRUZ BIOTECHNOLOGY) at $4^{\circ} \mathrm{C}$ over-night, followed by washing and incubation with the secondary antibody Goat anti-Mouse $\operatorname{IgG}(\mathrm{H}+$ L) DyLight 488 (Thermo Fischer Scientific). The nuclei of the cells were stained with DAPI mounting medium (VECTASHIELD, VECTOR LABORATORIES) according manufacturer's instructions. The detection of the fluorescence stained cells was performed with the Leica microscope DM 5000 B (Leica).

\section{Treatment of cell lines with PI3K inhibitors}

The cell lines MKL-1, MKL-2, WaGa, PeTa, MCC13, MCC26 and REH were treated with idelalisib (Selleckchem, Germany) and BYL719 (Selleckchem, Germany). Both agents were dissolved in DMSO. Following concentrations were used for the treatments: $10 \mathrm{nM}, 100 \mathrm{nM}, 500 \mathrm{nM}, 1 \mu \mathrm{M}, 12.5 \mu \mathrm{M}, 25 \mu \mathrm{M}, 50 \mu \mathrm{M}$ and $100 \mu \mathrm{M}$.

The cells were incubated in a 96 well plate (Greiner Bio-One, Austria) for $120 \mathrm{~h}$, in Gibco ${ }^{\circledR}$ RPMI 1640 medium (Life-science) with 10\% fetal calf serum (FCS) $\left(\right.$ Gibco $^{\circledR}$, Thermo Fisher Scientific) in an incubator at $37^{\circ} \mathrm{C}$ and $5 \% \mathrm{CO}_{2}$. The effect of the drug on the cell viability was assessed by the XTT assay (Thermo Fisher Scientific) according to the protocol provided by the manufacturer. The read out of the XTT assay was done with the iMark ${ }^{\mathrm{TM}}$ Microplate Absorbance Reader (BIO-RAD).

To determine the effect of idelalisib on the PI3K pathway the phosphorylation of AKT was assessed by Western blotting. Therefore, the cells were treated with $0.2 \%$ DMSO, $1 \mu \mathrm{M}, 12.5 \mu \mathrm{M}$ and $25 \mu \mathrm{M}$ of idelalisib for $72 \mathrm{~h}$.

\section{Statistics}

The half maximal inhibitory concentration $\left(\mathrm{IC}_{50}\right)$ values were determined with Graphpad Prism 6. By using the One-Way ANOVA test the significance of the dose response curves was determined. The western blots were quantified via ImageJ [24]. 


\section{CONCLUSIONS}

The tested MCCs and MCC cell lines express PI3K p $110 \delta$. However, the MCC cell lines seem to be resistant towards treatment with the specific p110 $\delta$-inhibitor idelalisib. Our data indicate that idelalisib monotherapy will not suffice to treat MCC. In as much MCC patients might benefit of a combination of radiotherapy and idelalisib remains to be elucidated by clinical studies.

\section{ACKNOWLEDGMENTS}

We would like to thank our colleagues from the Department of transplantation immunology, tissue typing laboratory, MUMC+ who provided us with the multiple myeloma cell line U266.

\section{CONFLICTS OF INTEREST}

The authors declare no conflicts of interest.

\section{REFERENCES}

1. Schadendorf D, Lebbé C, Zur Hausen A, Avril MF, Hariharan S, Bharmal M, Becker JC. Merkel cell carcinoma: Epidemiology, prognosis, therapy and unmet medical needs. Eur J Cancer. 2017; 71:53-69. https://doi. org/10.1016/j.ejca.2016.10.022.

2. Becker JC, Stang A, DeCaprio JA, Cerroni L, Lebbé C, Veness M, Nghiem P. Merkel cell carcinoma. Nat Rev Dis Primers. 2017; 3:17077. https://doi.org/10.1038/nrdp.2017.77.

3. Harms PW. Update on Merkel Cell Carcinoma. Clin Lab Med. 2017; 37:485-501. https://doi.org/10.1016/j.cll.2017.05.004.

4. Hughes MP, Hardee ME, Cornelius LA, Hutchins LF, Becker JC, Gao L. Merkel Cell Carcinoma: Epidemiology, Target, and Therapy. Curr Dermatol Rep. 2014; 3:46-53. https://doi.org/10.1007/s13671-014-0068-z.

5. Feng H, Shuda M, Chang Y, Moore PS. Clonal integration of a polyomavirus in human Merkel cell carcinoma. Science. 2008; 319:1096-100. https://doi.org/10.1126/ science. 1152586 .

6. Verhaegen ME, Mangelberger D, Harms PW, Vozheiko TD, Weick JW, Wilbert DM, Saunders TL, Ermilov AN, Bichakjian CK, Johnson TM, Imperiale MJ, Dlugosz AA. Merkel cell polyomavirus small $\mathrm{T}$ antigen is oncogenic in transgenic mice. J Invest Dermatol. 2015; 135:1415-24. https://doi.org/10.1038/jid.2014.446.

7. Kwun HJ, Wendzicki JA, Shuda Y, Moore PS, Chang Y. Merkel cell polyomavirus small $\mathrm{T}$ antigen induces genome instability by E3 ubiquitin ligase targeting. Oncogene. 2017; 36:6784-6792. https://www.nature.com/articles/ onc2017277\#supplementary-information.

8. Clarke CA, Robbins HA, Tatalovich Z, Lynch CF, Pawlish KS, Finch JL, Hernandez BY, Fraumeni JF Jr, Madeleine
MM, Engels EA. Risk of merkel cell carcinoma after solid organ transplantation. J Natl Cancer Inst. 2015; 107:dju382. https://doi.org/10.1093/jnci/dju382.

9. Engels EA, Frisch M, Goedert JJ, Biggar RJ, Miller RW. Merkel cell carcinoma and HIV infection. Lancet. 2002; 359:497-98. https://doi.org/10.1016/S0140-6736(02)07668-7.

10. Albores-Saavedra J, Batich K, Chable-Montero F, Sagy N, Schwartz AM, Henson DE. Merkel cell carcinoma demographics, morphology, and survival based on 3870 cases: a population based study. J Cutan Pathol. 2010; 37:20 27. https://doi.org/10.1111/j.1600-0560.2009.01370.x.

11. Shiver MB, Mahmoud F, Gao L. Response to Idelalisib in a Patient with Stage IV Merkel-Cell Carcinoma. N Engl J Med. 2015; 373:1580-82. https://doi.org/10.1056/NEJMc1507446.

12. Nardi V, Song Y, Santamaria-Barria JA, Cosper AK, Lam Q, Faber AC, Boland GM, Yeap BY, Bergethon K, Scialabba VL, Tsao H, Settleman J, Ryan DP, et al. Activation of PI3K signaling in Merkel cell carcinoma. Clin Cancer Res. 2012; 18:1227-36. https://doi.org/10.1158/1078-0432.CCR-11-2308.

13. Hafner C, Houben R, Baeurle A, Ritter C, Schrama D, Landthaler M, Becker JC. Activation of the PI3K/AKT pathway in Merkel cell carcinoma. PLoS One. 2012; 7:e31255. https://doi.org/10.1371/journal.pone.0031255.

14. Ikeda H, Hideshima T, Fulciniti M, Perrone G, Miura N, Yasui H, Okawa Y, Kiziltepe T, Santo L, Vallet S, Cristea $\mathrm{D}$, Calabrese E, Gorgun G, et al. PI3K/p110 $\{\delta\}$ is a novel therapeutic target in multiple myeloma. Blood. 2010; 116:1460-68. https://doi.org/10.1182/blood-2009-06-222943.

15. Beer-Hammer S, Zebedin E, von Holleben M, Alferink J, Reis B, Dresing P, Degrandi D, Scheu S, Hirsch E, Sexl V, Pfeffer K, Nürnberg B, Piekorz RP. The catalytic PI3K isoforms $\mathrm{p} 110 \gamma$ and $\mathrm{p} 110 \delta$ contribute to $\mathrm{B}$ cell development and maintenance, transformation, and proliferation. J Leukoc Biol. 2010; 87:1083-95. https://doi.org/10.1189/jlb.0809585.

16. Akinleye A, Avvaru P, Furqan M, Song Y, Liu D. Phosphatidylinositol 3-kinase (PI3K) inhibitors as cancer therapeutics. J Hematol Oncol. 2013; 6:88. https://doi. org/10.1186/1756-8722-6-88.

17. Vanhaesebroeck B, Welham MJ, Kotani K, Stein R, Warne PH, Zvelebil MJ, Higashi K, Volinia S, Downward J, Waterfield MD. P110delta, a novel phosphoinositide 3-kinase in leukocytes. Proc Natl Acad Sci USA. 1997; 94:4330-35. https://doi.org/10.1073/pnas.94.9.4330.

18. Zur Hausen A, Rennspiess D, Winnepenninckx V, Speel EJ, Kurz AK. Early B-cell differentiation in Merkel cell carcinomas: clues to cellular ancestry. Cancer Res. 2013; 73:4982-87. https://doi.org/10.1158/0008-5472.CAN-13-0616.

19. Murakami I, Takata K, Matsushita M, Nonaka D, Iwasaki T, Kuwamoto S, Kato M, Mohri T, Nagata K, Kitamura Y, Yoshino T, Hayashi K. Immunoglobulin expressions are only associated with MCPyV-positive Merkel cell carcinomas but not with MCPyV-negative ones: comparison of prognosis. Am J Surg Pathol. 2014; 38:1627-35. https:// doi.org/10.1097/PAS.0000000000000279. 
20. Sorensen R, Meadows S, Yahiaoui A, Li L, Yue P, Kashishian A, Queva C, Tannheimer S. Investigation of the Mechanism of Idelalisib Resistance in the Follicular Lymphoma WSU-Fsccl Cell Line. Blood. 2015; 126:2482.

21. Woyach JA. Patterns of resistance to B cell-receptor pathway antagonists in chronic lymphocytic leukemia and strategies for management. Hematology Am Soc Hematol Educ Program. 2015; 2015:355-60. https://doi.org/10.1182/ asheducation-2015.1.355.

22. Cheah CY, Fowler NH. Idelalisib in the management of lymphoma. Blood. 2016; 128:331-36. https://doi. org/10.1182/blood-2016-02-702761.
23. Iyer JG, Parvathaneni U, Gooley T, Miller NJ, Markowitz E, Blom A, Lewis CW, Doumani RF, Parvathaneni K, Anderson A, Bestick A, Liao J, Kane G, et al. Singlefraction radiation therapy in patients with metastatic Merkel cell carcinoma. Cancer Med. 2015; 4:1161-70. https://doi. org/10.1002/cam4.458.

24. Schneider CA, Rasband WS, Eliceiri KW. NIH Image to ImageJ: 25 years of image analysis. Nat Methods. 2012; 9:671-75. https://doi.org/10.1038/nmeth.2089. 